\title{
MODELLING THE MATERIAL PROPERTIES AND BEHAVIOUR OF NI- AND NIFE-BASED SUPERALLOYS
}

\author{
N. Saunders ${ }^{1}$, Z. Guo ${ }^{2}$, A.P. Miodownik ${ }^{2}$, J-Ph. Schillé ${ }^{2}$ \\ ${ }^{1}$ Thermotech Ltd., Surrey Technology Centre, The Surrey Research Park, \\ Guildford GU2 7YG, U.K. \\ ${ }^{2}$ Sente Software Ltd., Surrey Technology Centre, The Surrey Research Park, \\ Guildford GU2 7YG, U.K.
}

Keywords: modelling, high temperature mechanical properties, high temperature stress/strain diagrams, physical properties, solidification, TTT diagram, CCT diagram

\begin{abstract}
Over the past decade thermodynamic models have become increasingly used for $\mathrm{Ni}$ - and $\mathrm{NiFe}-$ based superalloys. However, their applicability often falls short from directly providing the information that is actually required. To overcome such limitations a new computer programme has been developed, called JMatPro (an acronym for Java-based Materials Properties software). The properties which can be calculated are wide ranging, including thermo-physical and physical properties (from room temperature to the liquid state), TTT/CCT diagrams, coarsening of $\gamma^{\prime}$ and $\gamma^{\prime \prime}$, and mechanical properties. It should be noted that the mechanical properties are calculated as a function of temperature and strain rate up to the melting point. Stress/strain diagrams at any given temperature and strain rate can also be generated. The creep properties that JMatPro provides include steady creep rate, rupture life and rupture strength. A feature of the new programme is that the calculations are based, as far as possible, on sound physical principles rather than purely statistical methods. Thus many of the shortcomings of methods such as regression analysis can be overcome. It allows sensitivity to microstructure to be included for many of the properties and also means that the true inter-relationship between properties can be developed, e.g. in the modelling of creep and precipitation hardening. The purpose of the present paper is to describe the technical background behind the new programme, giving extensive examples of its application and use for superalloys of the 718, 625, 706 and derivative types.
\end{abstract}

\section{Introduction}

Tools that utilise thermodynamic modelling for exploring the equilibrium and phase relationships in complex materials are being increasingly used in industrial practice for Ni- and $\mathrm{NiFe}$-based superalloys [1,2]. These tools provide significant benefit, but their applicability often falls short from directly providing the information that is actually required. For example, thermodynamic modelling helps towards the understanding of changes in phase constitution of a material as a function of composition or temperature. However, there is then a gap in translating this information into the properties being targeted by the end user, e.g. TTT diagrams, mechanical properties, thermo-physical and physical properties.

To overcome these limitations a new computer programme has been developed [3], called JMatPro, an acronym for Java-based Materials Properties software. The approach adopted in the development of the new programme has been to augment the thermodynamic calculation by incorporating various theoretical materials models and properties databases that allow a quantitative calculation for the requisite materials property to be made within a larger software 
structure. The purpose of the present paper is to describe the technical background behind the new programme, and review its use and application to $\mathrm{Ni}$ - and NiFe-based superalloys.

\section{Applications}

$\underline{\text { Thermo-physical and Physical Properties }}$

In the Solid State

A major achievement of the JMatPro software project has been the development of an extensive database for the calculation of physical properties that can be linked to its thermodynamic calculation capability [4]. For individual phases in multi-component systems, properties, such as molar volume, thermal conductivity, Young's modulus, Poisson's ratio, etc., are calculated using simple pair-wise mixture models, similar to those used to model thermodynamic excess functions in multi-component alloys. Once the property of the individual phase is defined, the property of the final alloy can be calculated using mixture models that can account for the effect of microstructure on the final property [5,6]. Such models, which were developed for two-phase systems, have been extended to allow calculations to be made for multi-phase structures [7].

Utilising well established relationships between certain properties, (e.g. thermal and electrical conductivity), allows other properties to be calculated without using further databases, so that the following properties can be modelled - volume, density, expansion coefficient, Young's, bulk and shear moduli, Poisson's ratio, thermal conductivity and diffusivity, electrical conductivity and resistivity, viscosity and diffusivity of the liquid.

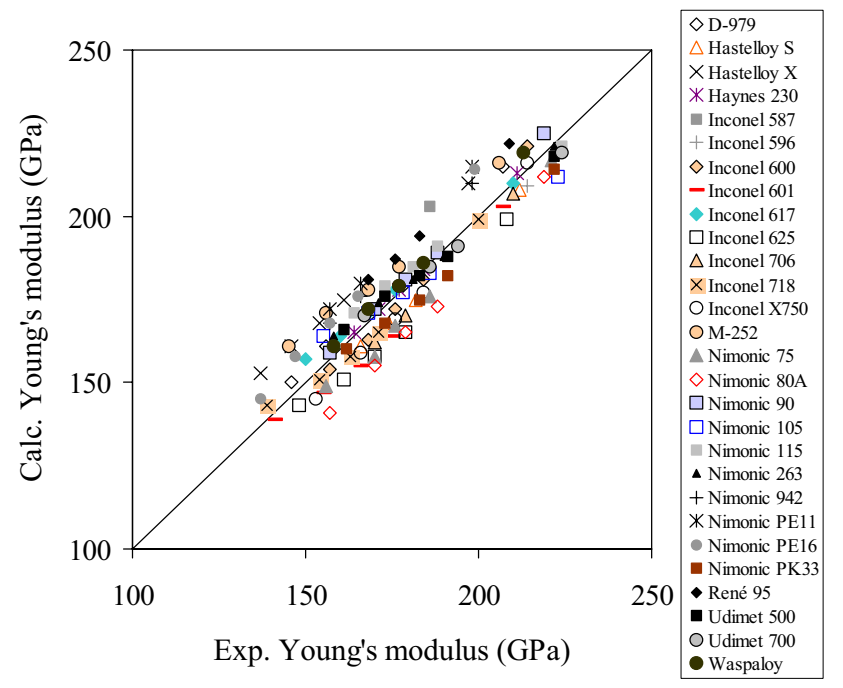

Figure 1. Comparison between experimental [8] and calculated Young's modulus for various disk alloys.

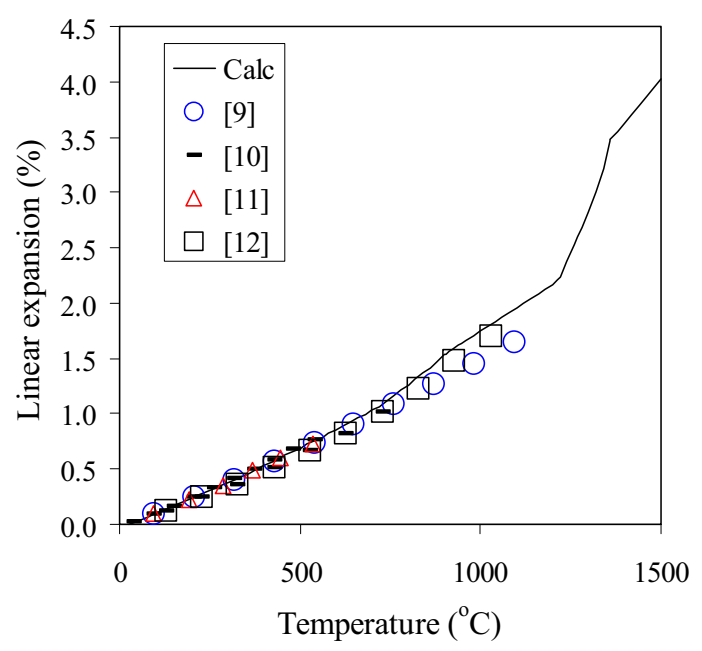

Figure 2. Comparison between experimental and calculated linear expansion for a 718 alloy.

Figure 1 compares experimental [8] and calculated Young's modulus for various wrought alloys between room temperature (RT) and $870^{\circ} \mathrm{C}$, while Figure 2 shows a comparison between calculated and experimental $[9,10,11,12]$ linear expansion for 718 alloys. For $\gamma$ alloys such as the Hastelloy series, the phase constitution changes little, if at all, in the temperature range of interest. However, for $\gamma^{\prime} / \gamma^{\prime \prime}$ alloys this assumption is not valid. The calculations have therefore been made assuming that the phases present below the final heat treatment temperature (FHTT) are those calculated at the FHTT and kinetically "frozen in". Above the FHTT, the phases are allowed to equilibriate, which leads to, for example, the dissolution of $\gamma^{\prime}$ and $\gamma^{\prime \prime}$. The approach provides excellent results and is consistent with a simple $\sqrt{D t}$ calculation that suggests that in the region $750-850^{\circ} \mathrm{C}$ (where most $\gamma^{\prime} / \gamma^{\prime \prime}$ wrought alloys are heat treated) diffusion distances would become comparable to those of $\gamma^{\prime} / \gamma^{\prime \prime}$ particle spacings. 
In the Liquid State

The thermo-physical and physical properties of the liquid and solid phases are critical components in casting simulations. However, due to the difficulty in experimentally determining such properties at solidification temperatures, little information exists for multi-component alloys. The calculation of physical properties has therefore been extended to include them for solidification.

Recently the application of so-called "Scheil-Gulliver" (SG) modelling via a thermodynamic calculation route has led to the ability to predict a number of critical thermo-physical properties for alloys such as Ni-based superalloys $[13,14]$. Such calculations can be computationally very fast and readily used within solidification packages. The model assumes that solute diffusion in the solid phase is slow enough to be considered negligible and that diffusion in the liquid is fast enough to assume that diffusion is complete. While it is known that some back diffusion will occur, for many alloy types, including most Ni-based superalloys, the SG assumption leads to good results for much of the solidification range and can be used to obtain high quality input for casting simulations.

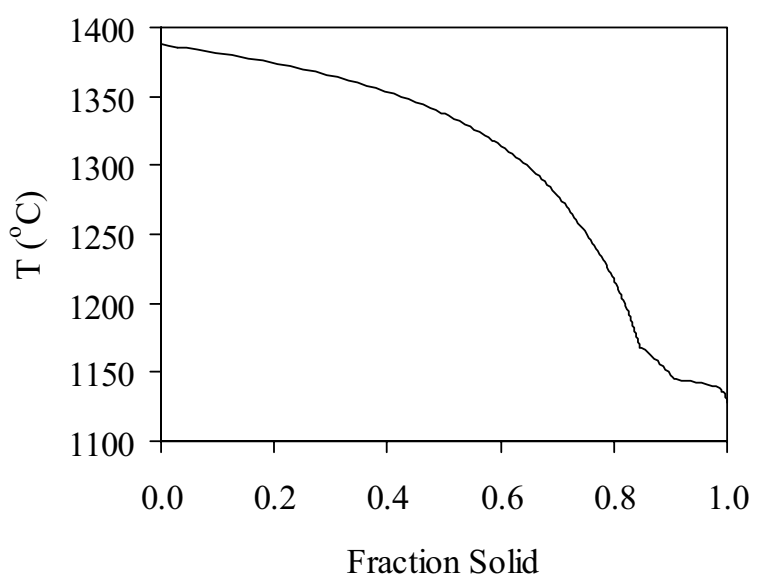

Figure 3. Calculated fraction solid vs. temperature plot for the solidification of alloy 706 .

Figure 3 shows the calculated fraction vs temperature plot for alloy 706, while Table I shows the comparison between calculated and experimental transformation temperatures. $\eta$ is observed in solidified 706, though its formation temperature could not be discerned experimentally. At the completion of solidification, JMatPro retains information about the solid phases formed during solidification and extrapolates their properties below the solidus. Calculation of properties can therefore be continued to low temperatures, enabling properties to be supplied for the whole mesh in a casting simulation (not just the liquid and mushy zone).

Table I. Comparison between experimental DTA results and a Scheil-Gulliver simulation for a 706 alloy

\begin{tabular}{cccccc}
\hline & Liquidus & $\begin{array}{c}\text { MC } \\
\text { start }\end{array}$ & $\begin{array}{c}\text { Laves } \\
\text { start }\end{array}$ & $\begin{array}{c}\eta \\
\text { start }\end{array}$ & $\begin{array}{c}\text { Solidifi- } \\
\text { cation end }\end{array}$ \\
\hline Centre (DTA) & 1381 & 1240 & 1164 & & \\
Edge (DTA) & 1388 & 1261 & & & \\
Calculated & 1388 & 1256 & 1168 & 1144 & 1128 \\
\hline
\end{tabular}

The physical properties of the liquid phase have been extensively modelled and combined with Scheil-Gulliver based calculations and physical properties for the solid state to provide soundly based changes in physical properties during the casting process $[4,15,16]$. Fine detail can be obtained, for example the density of the liquid in the mushy zone (Figure 4), which can be utilised for the calculation of casting defects and, potentially, macrosegregation in ingot casting and re-melting processes. With respect to the latter case, Figure 4 shows the density variation of the liquid phase in the mushy zone for three superalloys, showing the quite different behaviour of alloy 706, which shows signs of a density inversion, in comparison to 718 and 625 . Such 
behaviour is consistent with observations of defects in re-melted alloys and the various calculations of liquid density of Auburtin et al. [17].

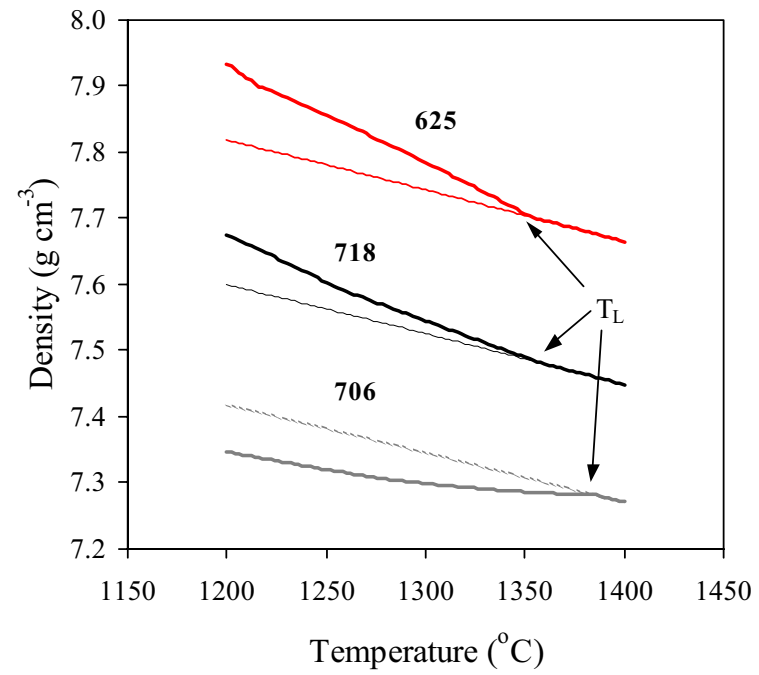

Figure 4. Calculated densities of the liquid phase during solidification of 625,718 and 706 alloys (bold lines). Fine lines show the density of the liquid alloys extrapolated from high temperature ( $\mathrm{T}_{\mathrm{L}}$ is the liquidus).

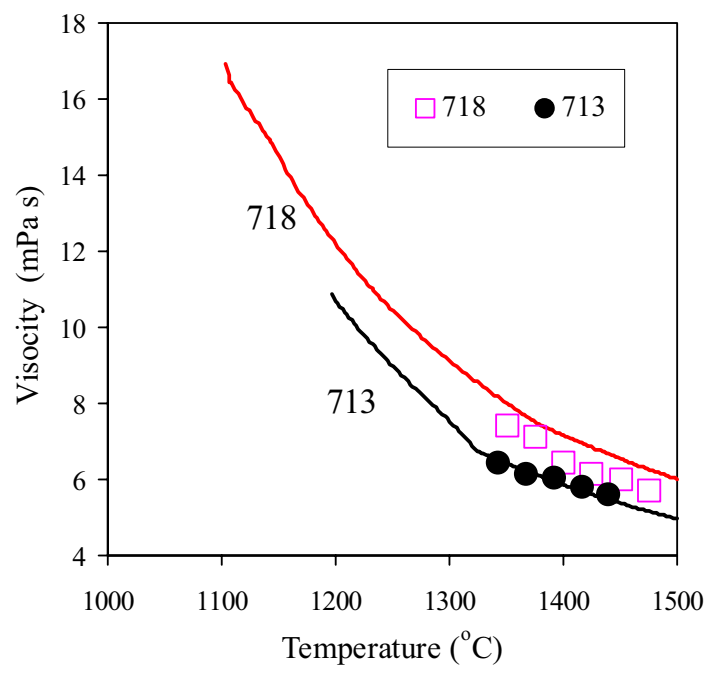

Figure 5. Calculated viscosity of the liquid during solidification of alloys 713 and 718 . Experimental data for the fully liquid state [18] shown for comparison.

In the calculation of the Rayleigh number and its application to defect formation it is also important to obtain liquid viscosities in the mushy zone. Figure 5 shows the calculated liquid viscosity in two alloys, 713 and 718, during solidification. Experimental measurements of the fully liquid alloys are shown for comparison [18]. It can be seen that a simple extrapolation of the high temperature liquid properties into the mushy zone will seriously underestimate the viscosity for both alloys.

In all cases of solidification, the properties of the liquid in the mushy zone are sensitive to partitioning of the various elements of the alloy. By combining the thermodynamic calculation with the physical property models it is now possible to explicitly consider the effect of changing liquid composition on a wide variety of physical properties.

\section{$\underline{\text { TTT and CCT Diagrams }}$}

An approach for the calculation of isothermal Time-Temperature-Transformation (TTT) and Continuous Cooling Transformation (CCT) diagrams has been described in previous papers $[3,19,20]$. Details of the scientific background are provided in [20]. The kinetic treatment is based on a modified Johnson-Mehl-Avrami model where critical input data, such as driving forces, compositions of the precipitating phases, etc. are obtained from thermodynamic calculations. Work has been undertaken to create the requisite diffusion database for Ni-alloys, assess the typical nucleation and shape characteristics for various types of precipitate, and validate the approach against experiment.

An advantage of the current modelling method is that only a few input parameters that need to be empirically evaluated. Where empirical values are used, for example, to account for shape of precipitates and nucleant density, specific values have been defined for the various precipitates. Once these values are defined, they have then been self-consistently applied and the model can therefore be used in a predictive fashion. 

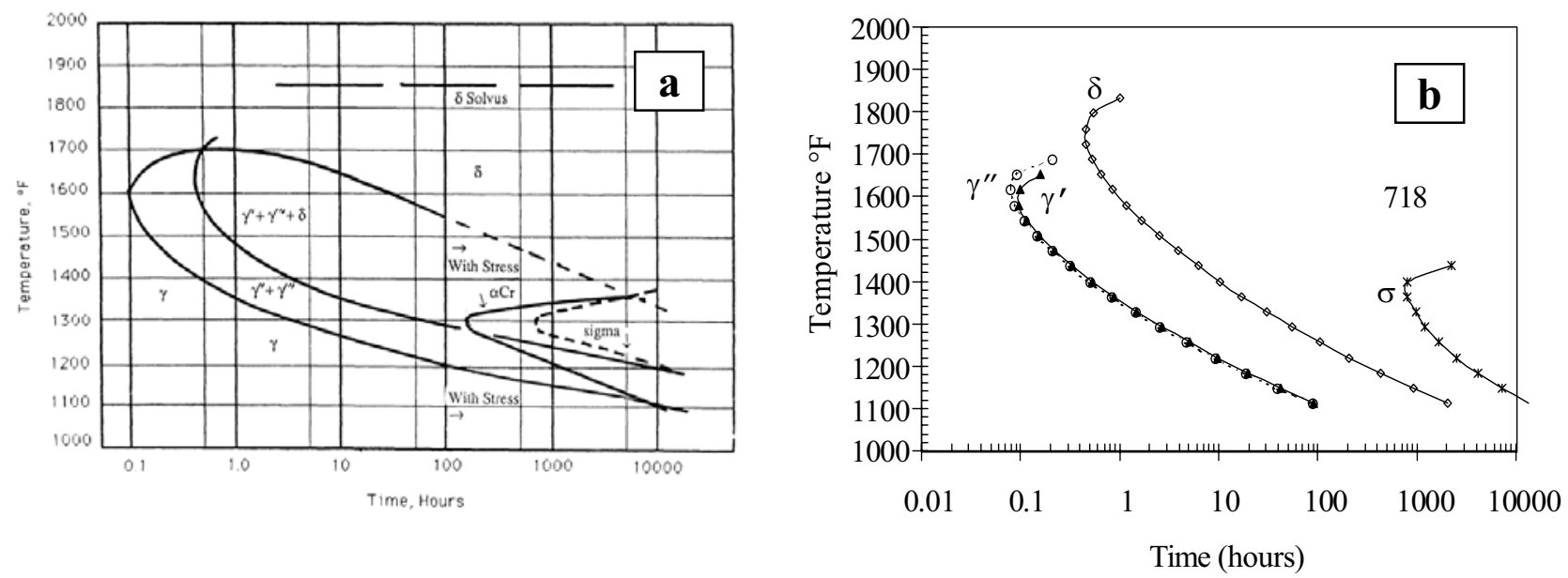

Figure 6. (a) Experimentally observed [21] and (b) calculated [4] TTT diagram for alloy 718.

Figure 6 shows the calculated TTT diagram [4] for a 718 alloy and compares it with experiment [21]. In this case the $\gamma^{\prime}, \gamma^{\prime \prime}$ and $\delta$ phases are considered to form from supersaturated $\gamma$, quenched from the solution temperature, while $\sigma$ forms from transformed $\gamma$ at the temperature of calculation.

For wrought $\gamma^{\prime} / \gamma^{\prime \prime}$ alloys, the CCT diagram is often of equal importance. It is possible to convert a TTT diagram to a CCT diagram using well-known additivity rules [22], and Figure 7 shows a calculated CCT diagram for alloy 706 .

\section{Mechanical Properties}

\section{Room Temperature Mechanical Properties}

Work has been previously reported [4] on modelling of the mechanical strength of solid solution and $\gamma^{\prime}$ and $\gamma^{\prime \prime}$ Ni- and NiFe-based superalloys. Using standard equations it has been possible to produce very accurate strength predictions for $\gamma^{\prime}$ alloys provided that the size of the $\gamma^{\prime}$ particles is known [4] (Figure 8).

Alloys such as 625 and 718 are strengthened by the $\gamma^{\prime \prime}$ phase, which has a greater strengthening potential than $\gamma^{\prime}$, in the context that the same amount of $\gamma^{\prime \prime}$ will provide substantially more strength than $\gamma^{\prime}$. For example, $0.2 \%$ proof stress in 718 can reach levels associated with alloys such as U720, which may have twice the volume fraction of $\gamma^{\prime}$ present. This can be explained by the significant lattice mismatch of $\gamma^{\prime \prime}$ along its major axis, which provides a further strain hardening contribution. Equations have been used to take this into account following the work of Oblak et al. [23]. The total particle strengthening

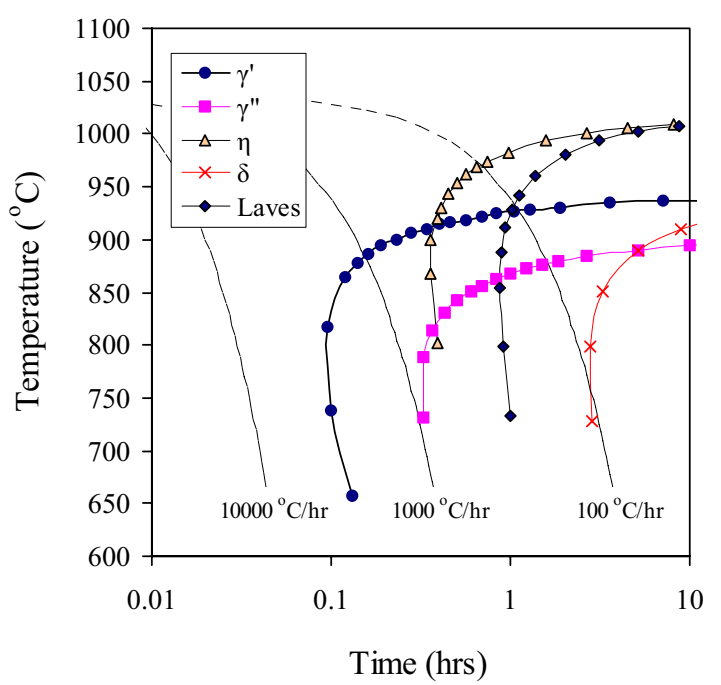

Figure 7. Calculated CCT diagram for alloy 706

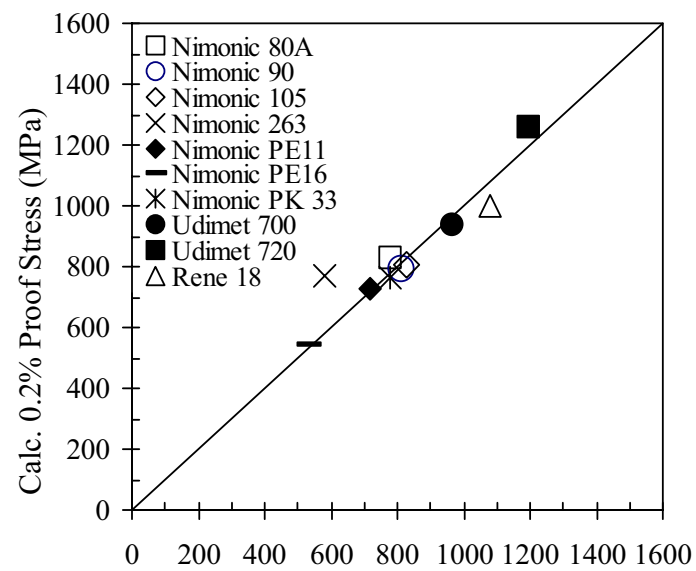

Exp. $0.2 \%$ Proof Stress (MPa)

Figure 8. Comparison between calculated and experimental $0.2 \%$ proof stress of various commercial Ni-based superalloys. 
contribution is considered to be a summation of that from strain hardening and dislocation cutting mechanisms.

Following the above scheme, calculations have been made for the room temperature strength of a 718 alloy based on a $\gamma$ grain size of $100 \mu \mathrm{m}$ and $\gamma^{\prime}$ and $\gamma^{\prime \prime}$ particle sizes of 15 and $25 \mathrm{~nm}$ respectively, taken from Chaturvedi and Han [24], which is consistent with other studies of 718 and variants $[25,26]$. The $0.2 \%$ proof stress is calculated as $1223 \mathrm{MPa}$ in comparison to the range found in commercial 718 alloys of 1185-1365 $\mathrm{MPa}$.

\section{High Temperature Mechanical Properties}

In previous papers $[3,4]$ it has been demonstrated that the temperature dependence of the yield stress for many $\mathrm{Ni}$ - and NiFe-based superalloys is well described by combining a model describing the decay in room temperature yield stress as a function of temperature, called here low temperature yield (LTY), until a sufficiently high temperature is reached where deformation becomes governed by creep flow and the yield stress falls sharply. An example of such behaviour is given in Figure 9.

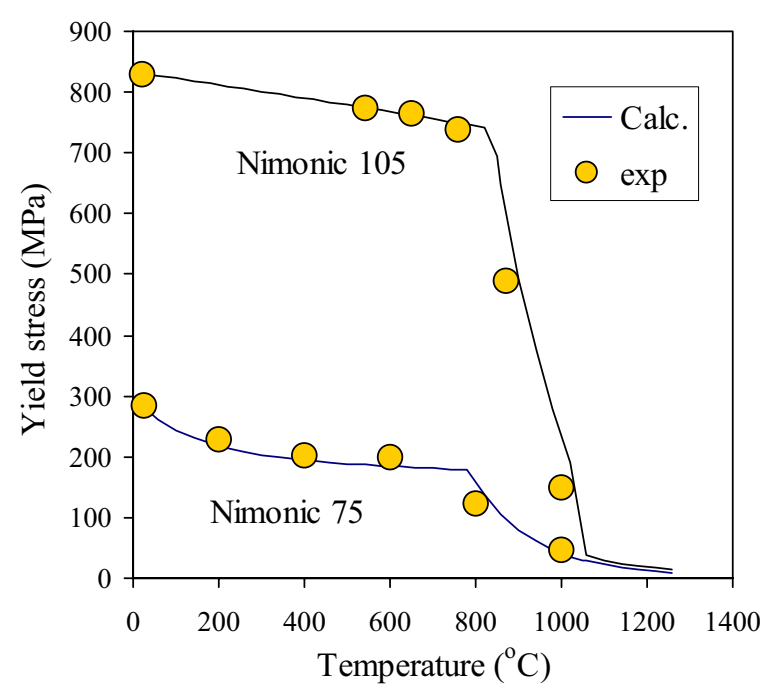

Figure 9. Comparison between experimental [27] and calculated yield stress for Nimonic 75 and 105 as a function of temperature.
The secondary creep model, which has been described previously $[4,28]$, has been extended to include primary and tertiary creep. It is now therefore possible to calculate full creep curves as a function of applied stress, which then allows the construction of a 3-dimensional surface that has as its axes stress, strain and time.

Assuming that the strain-rate in a tensile test and the creep rate in creep testing are interchangeable, it is then possible to calculate stress/strain curves at specific strain rates.

Combining this procedure with stress/strain curves calculated for the LTY region [29] allows stress/strain curves to be calculated over the full range of temperatures, potentially including the mushy zone.

The extended creep model used here follows the work of [30] which describes primary creep as:

$$
\dot{\varepsilon}_{p}=\frac{\dot{\varepsilon}_{s}}{K} \ln \left[1+\frac{\dot{\varepsilon}_{i}-\dot{\varepsilon}_{s}}{\dot{\varepsilon}_{s}}\left(1-e^{-K t}\right)\right]
$$

Where $\dot{\varepsilon}_{p}$ and $\dot{\varepsilon}_{s}$ are respectively the primary and secondary creep rates, $\dot{\varepsilon}_{i}$ is the initial creep rate and $K$ is an empirically evaluated materials constant. In the present case we have made $\dot{\varepsilon}_{i}=b \dot{\varepsilon}_{s}$, where $b$ is a simple proportionality constant. To account for tertiary creep we have used a somewhat empirical model that relates the tertiary creep rate to the secondary rate and the creep rupture life.

$$
\dot{\varepsilon}_{t}=\dot{\varepsilon}_{s} t\left[2 C_{d}\left(t / R_{l}\right)^{4}\right]
$$


where $\dot{\varepsilon}_{t}$ is the tertiary creep rate, $C_{d}$ is a "damage constant" and $R_{l}$ is the rupture life, which can be readily calculated by combining the secondary creep rate and a Monkman-Grant type relationship [4,28].

The behaviour of 706 and 718 alloys in the high temperature $\gamma$ phase field is used to demonstrate our approach. This is the region where these alloys are thermo-mechanically processed and where the modelling is likely to have most application. Figure 10 shows creep curves for 718 at various applied stresses at $1000^{\circ} \mathrm{C}$. In this case, the creep curve is calculated for true stress conditions, but it is possible to also calculate for constant load.

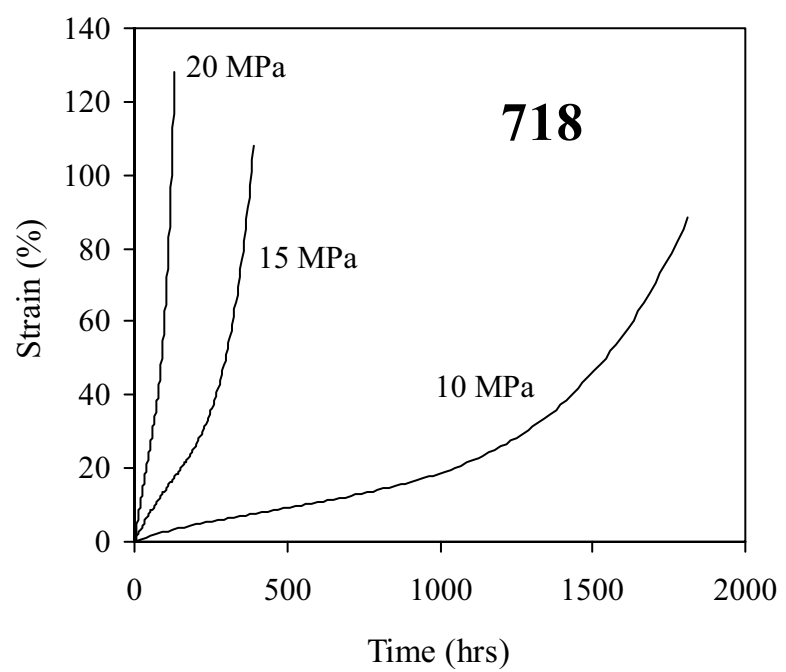

Figure 10. Calculated creep curves for a 718 alloy at $1000^{\circ} \mathrm{C}$

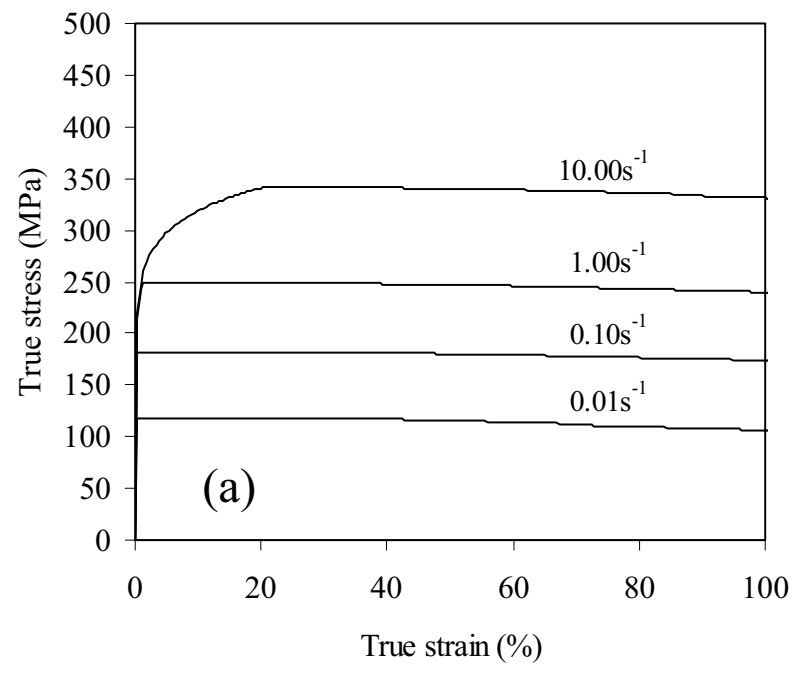

The curves exhibit a classical shape, with a clearly resolvable primary creep region that decays to leave a period of "steady state creep", but which in reality already has some contribution from tertiary creep. The final rapid increase in strain rate leads to failure. Finer detail of the method used here to calculate the curves as well as a fuller discussion of features of the model will be given in a future paper.

With such curves now in place it simple to construct the 3-dimensional surface previously described and to apply the model to the calculation of stress strain curves.

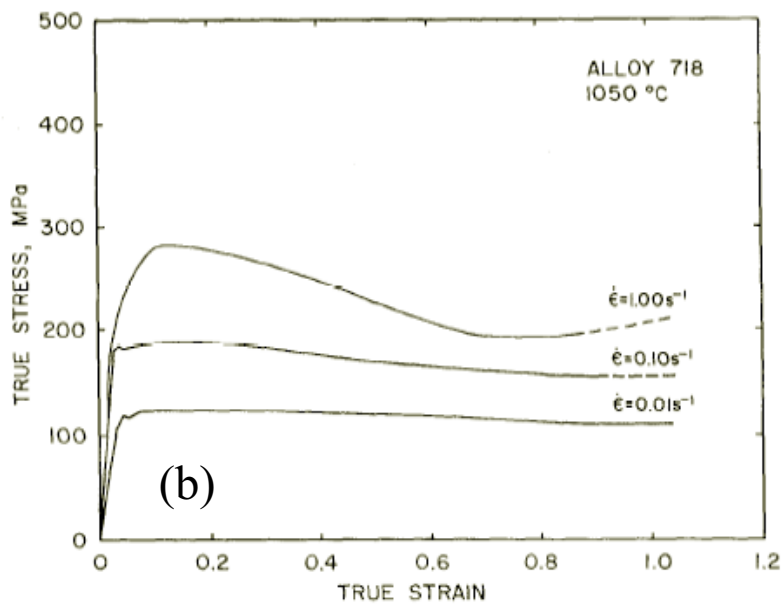

Figure 11. (a) Calculated and (b) experimentally observed stress/strain curves for 718 at $1050^{\circ} \mathrm{C}$.

Figure 11(a) shows the calculated stress/strain curves for 718 at $1050^{\circ} \mathrm{C}$, with experimental results of Weis et al [31] for comparison in Figure 11(b). The calculations show two distinct regions of behaviour. At 0.01 and $0.1 \mathrm{~s}^{-1}$ the alloys are deforming in a fully creep mode. In this case the comparison is extremely good. It can be seen that there is some slight flow softening, but the curves are rather flat over the whole strain range. This is very consistent with observed behaviour. 
At 1 and $10 \mathrm{~s}^{-1}$ the alloys are predicted to be deforming in a mixed mode. Initially, deformation is via a LTY mechanism (yield stresses are calculated to between 210 and $220 \mathrm{MPa}$ ) but, at a certain critical strain, work hardening raises the flow stress above the creep flow regime and the alloy is then predicted to flow by creep. The form of the curve underestimates the flow softening, because no flow-softening model via recrystallisation is yet in place for LTY deformation, which may provide a lower stress deformation mode. However, it will be seen in the next figures that results of the stress strain calculation in this region are still very useable and provide rather good predictions for the maximum flow stress.
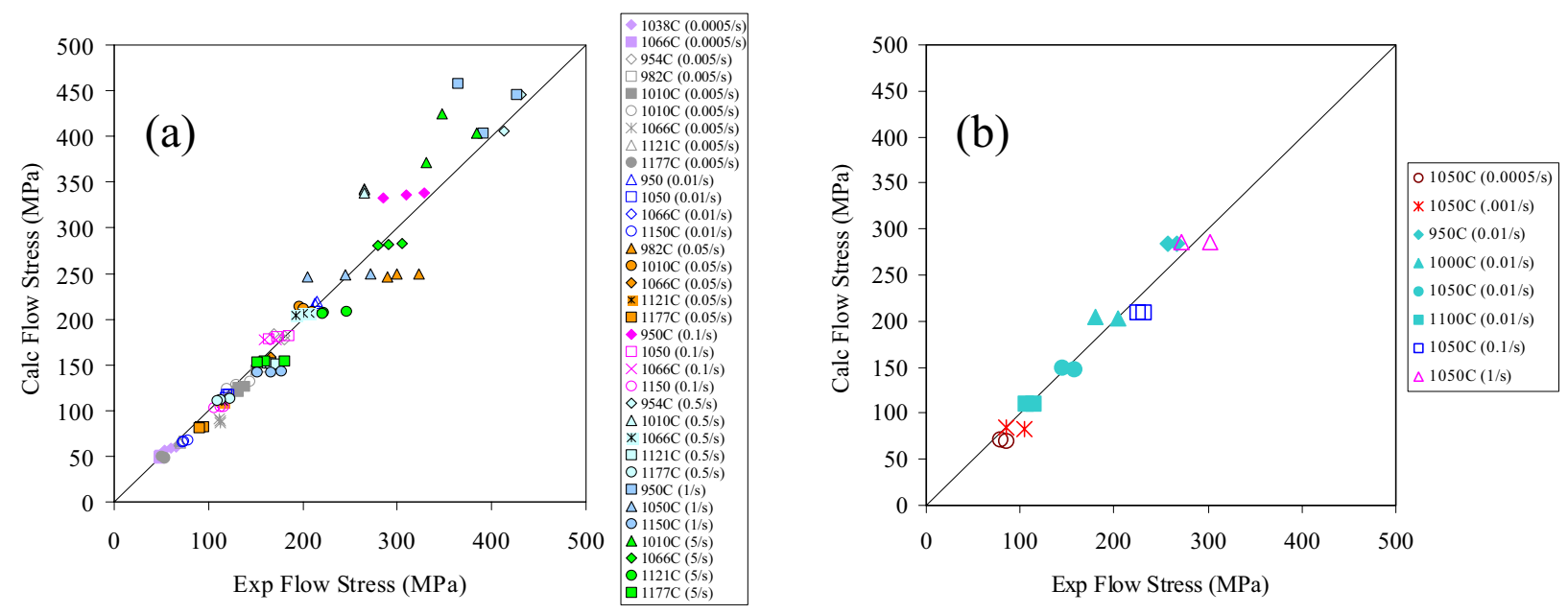

Figure 12. Comparison between calculated and experimental flow stress [31,32,33,34] at various strain rates and temperatures for (a) 718 and (b) 706 .

Figures 12(a) and 12(b) show comparison of calculated and experimentally observed flow stresses [31,32,33,34,35] at various strains between $10 \%$ and $60 \%$ over a wide range of temperatures for 718 and 706 respectively. The results are highly satisfactory, even when stresses move the curves into the mixed deformation regime.

The results of the calculations are very encouraging. Although it is often argued that flow softening is mainly controlled by recovery and recrystallisation process, it is clear that extremely good agreement with experiment is found using a creep model. The experimentally observed onset of flow softening at the higher strain rates (and/or lower temperatures) as, for example, observed in the curve for $1.0 \mathrm{~s}^{-1}$ in Figure 11 seems quite comparable to calculations based on "creep softening". This does pose the question as to whether the onset of recovery and recrystallisation processes is linked to the point where creep softening occurs. At the present time, it is not possible to come to any conclusions, but further work will be undertaken to include a flow softening model for the LTY regime.

\section{Summary and Conclusions}

This paper has reviewed the progress made in the development of a new computer programme, JMatPro, which calculates the materials properties and behaviour of complex multi-component $\mathrm{Ni}$ - and NiFe-based superalloys. The new programme emphasises calculation methods that are based on sound physical principles rather than purely statistical methods, hence the shortcomings of methods such as regression analysis are overcome.

The inclusion of microstructurally sensitive parameters means that it is possible to make the link with materials models that are currently being developed for prediction of microstructure. Such 
links will accelerate the development of a true virtual capability for design and optimisation of casting processes and thermo-mechanical heat treatment schedules for new alloys as well as existing ones.

The use of physically based models also means that the true inter-relationship between properties has been developed for complex situations such as in the modelling of creep and precipitation hardening. A key factor in the success of the approach has been the extensive validation of calculated results against experiment.

As well as providing a review of past work, the current paper has also described on-going work for the development of a model to calculate flow stress at high temperatures and extensively compared predictions against experiment for 706 and 718. The model indicates that there will be at least three regimes of behaviour.

The first regime corresponds to an extrapolation of low temperature yield behaviour (LTY), whereby flow stress can be modeled using standard formulations for stress/strain behaviour. At sufficiently high temperature there is a regime where flow is controlled by creep and highly accurate results can be obtained for flow stress as a function of strain, strain rate and temperature. This work also suggests the possibility of a mixed regime where the alloy initially yields by conventional dislocation yield, but strain hardening raises flow stresses above a point where the alloy becomes weaker due to creep, giving rise to flow softening. While recognizing the model requires an incorporation of softening due to recovery and recrystallisation in the LTY model, it nonetheless provides very useable results and provides rather good predictions for maximum flow stress.

\section{References}

1. N. Saunders, Superalloys 1996, eds. R. Kissinger et al. (Warrendale, PA: TMS, 1996), p.115

2 N. Saunders, M.Fahrmann and C.J. Small, Superalloys 2000, eds. K. A. Green et al (Warrendale, PA: TMS, 2000), p.803.

3. N. Saunders, Z. Guo, X. Li, A.P. Miodownik and J-Ph. Schillé, JOM, 55(12) (2003), 60.

4. N. Saunders, Z. Guo, X. Li, A.P. Miodownik and J-Ph. Schillé, "Superalloys 2004", Eds. K.A. Green et al., (TMS, Warrendale, PA, 2004), p.849.

5. Z. Fan, P. Tsakiropoulos and A.P. Miodownik, J. Mat. Sci., 29 (1994) p.141.

6. Z. Fan, Phil. Mag. A, 73 (1996), p.1663.

7. A.P. Miodownik, N. Saunders and J.-P. Schillé, unpublished research.

8. Adv. Mater. Proc., 156 (6), (1999), p.80.

9. J. Valentich, Prod.Eng., (1965), p.63.

10. Aerojet-General Corp. rept. AGC-4-433, DVR-63-566 (1963).

11. J.H. Heathman, U.S. Air Force Rept., AFFDL-TR-68-75-Vol.1 (1968).

12. V.S. Babu, A.S. Pavlovic and M.S. Seera, "Superalloy 718, 625, 706 and Derivatives"

ed. E.A. Loria (TMS, Warrendale, PA), p.689.

13. W.J. Boettinger, U.R. Kattner, S.R. Coriell, Y.A. Chang and B.A Mueller, Modeling of Casting, Welding and Advanced Solidification Processes, VII, eds. M. Cross et al. (Warrendale, PA: TMS, 1995), p.649.

14. N. Saunders, Solidification Processing 1997, eds. J. Beech and H. Jones, (Sheffield: Univ.Sheffield, 1997), 362.

15. N. Saunders, X. Li. A.P. Miodownik and J.-Ph. Schillé, Modelling of Casting, Welding and Advanced Solidification Processes X, eds. D. Stefanescu et al., (Warrendale, PA: TMS, 2003), 669.

16. N. Saunders, A.P. Miodownik and J.-Ph. Schillé, J.Mater.Sci., 39, (2004), p.7237. 
17. P. Auburtin, S.L. Cockcroft, A. Mitchell and A.J. Schmalz, Superalloys 718, 625, 706 and Various Derivatives, ed. E.A. Loria, (Warrendale, PA: TMS, 1997), 47.

18. Data downloaded from Auburn University's Materials Processing Center website, June 2003. (Web address http://metalcasting.auburn.edu/data/data.html).

19. N. Saunders, X. Li, A.P. Miodownik and J-Ph. Schillé, Materials Design Approaches and Experiences, eds. J.-C. Zhao et al., (Warrendale, PA:TMS, 2001), 185.

20. X. Li, A.P. Miodownik and N. Saunders, Mater. Sci. Tech., 18, (2002), 861.

21. A. Oradei-Basile and J.F. Radavich, Superalloys 718, 625 and Various Derivatives, ed. E.A. Loria, (Warrendale, PA: TMS, 1991), 325.

22. J. S. Kirkaldy, Scand. J. Metall., 20 (1991), 50.

23. J.M. Oblak, D.S. Duvall and D.F. Paulonis, Mat. Sci. Eng., 13 (1974), 51.

24. M.C. Chaturvedi and Y. Han, Superalloy 718-Metallurgy and Applications, ed. E.A. Loria, (Warrendale, PA: TMS, 1989), 489.

25. M. Sundararaman P. Mukhopadhyay and S. Banerjee, Metall. Trans. A, 23A (1992), 2015.

26. E. Guo, F. Xu and E.A. Loria, Superalloys 718,625 and Various Derivatives, ed. E.A. Loria, (Warrendale, PA: TMS, 1991), 397.

27. W. Betteridge and J. Heslop, The NIMONIC Alloys and Other Ni-Base High Temperature Alloys: 2nd ed., (London: Edward Arnold Ltd, 1974).

28. A.P. Miodownik, X. Li, N. Saunders and J.-P. Schille, Parsons 2003: Engineering Issues in Turbine Machinery, Power Plant and Renewables, eds. A. Strang et al., (London: Inst.MMM, 2003), 779.

29. X. Li, A. P. Miodownik and N. Saunders, J. Phase Equilibria, 22 (2001), 247.

30. J.C.M. Li, Acta Metall., 11, (1963), 1269.

31. M.J. Weis, M.C. Mataya, S.W. Thompson and D.K. Matlock, Superalloy 718, ed. E.A. Loria, (Warrendale, PA: TMS, 1989), 135.

32. C.I. Garcia, G.D. Wang, D.E. Camus, E.A. Loria and A.J. DeArdo, Superalloys 718,625, 706 and Various Derivatives, ed. E.A. Loria, (Warrendale, PA: TMS, 1994), 293.

33. D. Zhao, S. Guillard and A.T. Male, Superalloys 718,625, 706 and Various Derivatives, ed. E.A. Loria, (Warrendale, PA: TMS, 1997), 193.

34. N.K.Park, J.T. Yum, Y.S. Na, I.S. Kim, D.H. Kim and S.J. Choe, Superalloys 718,625, 706 and Various Derivatives, ed. E.A. Loria, (Warrendale, PA: TMS, 1997), 173.

35. Z. Long, D. Fu, P. Ma, Z. Zhong, Superalloys 718,625, 706 and Various Derivatives, ed. E.A. Loria, (Warrendale, PA: TMS, 1997), 205. 